\title{
Modified Primers for the Identification of Nonpathogenic Fusarium oxysporum Isolates That Have Biological Control Potential against Fusarium Wilt of Cucumber in Taiwan
}

\author{
Chaojen Wang ${ }^{1}$, Yisheng Lin ${ }^{2}$, Yinghong Lin ${ }^{1}$, Wenhsin Chung ${ }^{1 *}$ \\ 1 Department of Plant Pathology, National Chung Hsing University, Taichung, Taiwan, 2 Department of Biotechnology, Asia University, Wufeng, Taichung, Taiwan
}

\begin{abstract}
Previous investigations demonstrated that Fusarium oxysporum (Fo), which is not pathogenic to cucumbers, could serve as a biological control agent for managing Fusarium wilt of cucumber caused by Fo f. sp. cucumerinum (Foc) in Taiwan. However, thus far it has not been possible to separate the populations of pathogenic Fo from the nonpathogenic isolates that have biological control potential through their morphological characteristics. Although these two populations can be distinguished from one another using a bioassay, the work is laborious and time-consuming. In this study, a fragment of the intergenic spacer (IGS) region of ribosomal DNA from an Fo biological control agent, Fo366, was PCR-amplified with published general primers, FIGS11/FIGS12 and sequenced. A new primer, NPIGS-R, which was designed based on the IGS sequence, was paired with the FIGS11 primer. These primers were then evaluated for their specificity to amplify DNA from nonpathogenic Fo isolates that have biological control potential. The results showed that the modified primer pair, FIGS11/ NPIGS-R, amplified a 500-bp DNA fragment from five of seven nonpathogenic Fo isolates. These five Fo isolates delayed symptom development of cucumber Fusarium wilt in greenhouse bioassay tests. Seventy-seven Fo isolates were obtained from the soil and plant tissues and then subjected to amplification using the modified primer pair; six samples showed positive amplification. These six isolates did not cause symptoms on cucumber seedlings when grown in peat moss infested with the isolates and delayed disease development when the same plants were subsequently inoculated with a virulent isolate of Foc. Therefore, the modified primer pair may prove useful for the identification of Fo isolates that are nonpathogenic to cucumber which can potentially act as biocontrol agents for Fusarium wilt of cucumber.
\end{abstract}

Citation: Wang C, Lin Y, Lin Y, Chung W (2013) Modified Primers for the Identification of Nonpathogenic Fusarium oxysporum Isolates That Have Biological Control Potential against Fusarium Wilt of Cucumber in Taiwan. PLoS ONE 8(6): e65093. doi:10.1371/journal.pone.0065093

Editor: Sung-Hwan Yun, Soonchunhyang University, Republic of Korea

Received November 28, 2012; Accepted April 21, 2013; Published June 7, 2013

Copyright: ( $) 2013$ Wang et al. This is an open-access article distributed under the terms of the Creative Commons Attribution License, which permits unrestricted use, distribution, and reproduction in any medium, provided the original author and source are credited.

Funding: Funding for this project was provided by the Bureau of Animal and Plant Health Inspection and Quarantine in Taiwan. The project numbers were 98AS9.2.1-BQ-B2 and 99AS-9.2.2-BQ-B3. The funders had no role in study design, data collection and analysis, decision to publish, or preparation of the manuscript.

Competing Interests: The authors have declared that no competing interests exist.

*E-mail: wenchung@dragon.nchu.edu.tw

\section{Introduction}

Numerous formae speciales of Fusarium oxysporum $\left(F_{0}\right)$ Schlechtend:Fr. are important pathogens that cause wilt diseases in many different host plants. This species is a ubiquitous soil-inhabiting fungus that is also a normal constituent of fungal communities in the rhizospheres of plants [1], [2], [3]. Historically, pathogenic $F_{0}$ isolates showing high host specificity have been classified into more than 150 formae speciales based on plant species and cultivars they infect [4]. Among these formae speciales, F. oxysporum f. sp. cucumerinum $(F o c)$ is one of the important pathogens that causes cucumber Fusarium wilt in most production areas, including North America, Europe and Asia [5]. Currently, several methods are being employed to control this disease, including breeding for resistance, fungicide application, crop rotation, soil amendments, and biological control. However, breeding for resistance and crop rotation practices are time-consuming, and the use of fungicides can be environmentally hazardous [6]. Soil amendments are less hazardous to the environment, but efficacy often depends on soil structure and $\mathrm{pH}$ [7]. Among biocontrol agents evaluated for the control of Fusarium wilt caused by $F_{0}$ formae speciales, the use of nonpathogenic $F_{0}$ isolates appears to hold much promise.

Nonpathogenic $F_{0}$ isolates have been used for the control of Fusarium wilt caused by various $F_{0}$ formae speciales [8]. A nonpathogenic $F_{0}$ strain, Fo47, has been shown to be an effective biocontrol agent for managing Fusarium wilt in several vegetable and flower crops [9]. The introduction of nonpathogenic $F_{0}$ into the stems of sweet potatoes and carnations [10], [11] resulted in the control of Fusarium wilt diseases in each respective host. In Taiwan, there are several reports of nonpathogenic $F_{0}$ isolates found to be useful for the control of Fusarium wilt [12], [13]. Furthermore, Chen [12] reported that the $F_{0}$ isolate Fo366 reduced the severity of cucumber Fusarium wilt caused by Foc. However, Fravel et al. [8] and Alabouvette et al. [14] showed that not all nonpathogenic $F_{0}$ isolates are effective biocontrol agents. Screening nonpathogenic $F_{0}$ isolates to assess the potential to serve as biocontrol agents has been difficult and time consuming. Thus, establishing a new method for rapid and reliable identification of nonpathogenic $F_{0}$ isolates that have potential for use as biocontrol agents could be very beneficial. 
Polymerase chain reaction (PCR) is a useful tool for the molecular characterization of fungi [15]. Many reports indicate that fungal species with similar morphology can be further classified based on PCR results [16], [17], [18], [19]. The intraspecies diversity of several fungi, including formae speciales and races, has been further distinguished using the PGR approach [20], [21]. Recent studies showed that the intergenic spacer (IGS) region of ribosomal DNA (rDNA) is a source of phylogenetic markers in Fo [22], [23], [24], [25], [26] and that the region amplified with the general primers FIGS11/FIGS12 is suitable for the study of populations, including relationships among the $F_{0}$ isolates [22], [27]. The objectives of this study were to identify polymorphisms in the IGS region of rDNA that differentiate nonpathogenic from pathogenic $F_{0}$ isolates and to develop a method to assess the efficacy of nonpathogenic $F_{0}$ isolates for use as potential biocontrol agents to manage Fusarium wilt of cucumber.

\section{Materials and Methods}

\section{Fungal Isolates and Culture Conditions}

A total of 145 Fusarium spp. isolates were included in this study. They were selected to represent the diversity among formae speciales and locations of origin in Taiwan (Table 1). One hundred and twenty two isolates represented 15 different formae speciales; of these isolates, six were $F o c$ isolates, including the ATCG16416 type. Also included in the 122 isolates were seven $F o c$ vegetative compatibility group (VCG) type strains (ATCC204373-379) and four VCG type strains (ATCC204369-372) of Fo f. sp. radiciscucumerinum (Forc). The remaining $15 F_{0}$ isolates were nonpathogenic to cucumber (Fo276, Fo366, Fo95020, Fo95021, Fo95022, Fo95024, Fo95026) and tomato (AV-006, AV-007, AV-010, AV011, AV-012, AV-013-1, AV-013-2, AV-014) (provided from AVRDC, unpublished data) from Taiwan, and eight isolates of seven other Fusarium spp. (F. concentricum, F. decemcellulare, F. equiseti, $F$. moniliforme, $F$. proliferatum, $F$. solani and $F$. verticillioides) were used in this study (Table 1). These 15 nonpathogenic $F_{0}$ isolates were recovered from the soil or plant tissues by plating on quintozene peptone agar (PCNB) medium [28]. These nonpathogenic isolates were shown to be nonpathogenic to cucumber or tomato seedlings [5].

For long-term storage of the cultures used in this study, single spore isolates were grown on PDA plates at $28^{\circ} \mathrm{C}$ for 5 days. Agar disks $(0.5 \mathrm{~cm}$ in diameter) were cut from the colony margins and transferred into test tubes $(12 \mathrm{~cm}$ in length, $1.5 \mathrm{~cm}$ in diameter) containing a soil-agar medium (1\% WA plus $10 \%$ loamy sand soil, autoclaved for $30 \mathrm{~min}$ at $\left.121^{\circ} \mathrm{C}, 15 \mathrm{lbs}\right)$. The tube cultures were incubated at room temperature, with caps kept loosely, until the soil-agar medium was dry. Then, the caps were tightened, and the cultures were stored at room temperature.

\section{Fungal DNA Extraction, PCR and Analysis of the IGS Region}

DNA extraction was conducted by the method of Saitoh et al. [29] with some modification. Ten- to fourteen-day-old mycelia from single spore isolates grown on potato dextrose agar (PDA) slants were transferred with an inoculation needle into a microtube containing $500 \mu \mathrm{l}$ lysis buffer $(200 \mathrm{mM}$ Tris-HCl, $50 \mathrm{mM}$ ethylenediaminetetraacetic acid, $200 \mathrm{mM} \mathrm{NaCl}, 1 \%$ n-lauroylsarcosine sodium salt, $\mathrm{pH}$ 8.0). The mycelia were dispersed in the buffer and incubated for 20 to $30 \mathrm{~min}$ at room temperature. The mixture was centrifuged at 18,000 $\mathrm{g}$ (Rotor: Nr. 12154, Sigma $3 \mathrm{k} 20$ ) for $10 \mathrm{~min}$ at $4^{\circ} \mathrm{C}$, and then the supernatant $(300 \mu \mathrm{l})$ was transferred into a new microtube. After the supernatant was mixed with $750 \mu \mathrm{l}$ of ethanol by inverting the tube, the DNA was precipitated by centrifugation at 18,000 $\mathrm{g}$ for $4 \mathrm{~min}$ at $4^{\circ} \mathrm{C}$. After one wash with $70 \%$ ethanol, the DNA pellet was air dried and dissolved in $50 \mu \mathrm{l}$ TE buffer ( $\mathrm{pH}$ 8.0). The PCR reactions were performed with genomic DNA from five selected $F_{0}$ isolates using the primer set FIGS11 (5' - GTAAGCGGTCGTTCGCGTCG $\left.3^{\prime}\right)$ /FIGS12 (5' - GCAAAATTCAATAGTATGGC - 3') to amplify a part of the IGS region [30]. The five selected isolates include the known nonpathogenic biocontrol isolate Fo366 and four formae speciales isolates identified as $F$. oxysporum $\mathrm{f}$. sp. cucumerinum (Foc100), F. oxysporum f. sp. luffae (Fol1 14), F. oxysporum f. sp. phaseoli (Fop04) and F. oxysporum f. sp. tracheiphilum (Fot60). Amplified DNA fragments were sequenced (Mission Biotech Co., Taiwan) and searched using the BLAST algorithm in GenBank from the National Center for Biotechnology Information (NCBI, Bethesda, MD).

\section{Primer Design and PCR Amplification}

To design a primer pair that could differentiate nonpathogenic $F_{0}$ isolates with biological control capability (Fo366) from pathogenic $F_{0}$ isolates, the partial IGS nucleotide sequence from the $F_{0}$ isolate Fo366 was submitted to GenBank under accession number AB683869 and used to compare with sequences from pathogenic $F_{0}$ isolates. In this study, there were 20 formae speciales gene sequences selected from the NCBI GenBank database (http://www.ncbi.nlm.nih.gov/genbank/index.html) that were used to compare with the identical region from Fo366. The isolates from different $F$. oxysporum formae speciales and accession numbers are as follows: apii (AB106048), asparagi (AB373827), cepae (AB306845), cubense (AY527732), gladioli (AB383677), glycines (AB373826), lactucae (AB373825), lagenariae (AB306847), lilii (AB383690), loti (EU313466), lycopersici (AB373820), matthiolae (AB306843), medicaginis (EU313446), melonis (AB306848), pisi (EU313451), radicis-lycopersici (AB373823), rapae (AB306834), raphani (AB306841), spinaciae (AB306844) and tulipae (EU313443). The alignment software Clustal X 1.81 was used to analyze the unique region of Fo366 and the above mentioned formae speciales, and the identical regions were used to design a new primer. For PGR amplification, the 25- $\mu$ l PCR mixture contained $1 \mu \mathrm{l}$ fungal DNA, PGR Master Mix (1.25 U Taq DNA polymerase, reaction buffer, $1.75 \mathrm{mM} \mathrm{MgCl}_{2}, 200 \mu \mathrm{M} \mathrm{dNTP}$ and enzyme stabilizer) (Genemark Technology Co., Ltd., Taiwan) and $0.2 \mu \mathrm{M}$ of each primer (FIGS11/FIGS12). The PCR reaction was performed under the following temperature cycles: $95^{\circ} \mathrm{C}$ for $2 \mathrm{~min}$, followed by 30 cycles of denaturing at $95^{\circ} \mathrm{C}$ for $30 \mathrm{sec}$, annealing at $58^{\circ} \mathrm{C}$ for $1 \mathrm{~min}$, and polymerizing at $72^{\circ} \mathrm{C}$ for $45 \mathrm{sec}$, and a final extension at $72^{\circ} \mathrm{C}$ for $10 \mathrm{~min}$. All the PCR reactions were conducted at three times to confirm reproducibility.

Specificity, Sensitivity and Application of the Primer Pair To assess the specificity of the primer pair FIGS11/NPIGS-R to detect nonpathogenic $F_{0}$ isolates, genomic DNA from the following 137 Fo isolates and 8 Fusarium spp. isolates were used as template DNA for the PCR assay: 15 formae speciales, which included one isolate each of chrysanthemi; 3 isolates each of basilici and phaseoli; 4 isolates each of luffae, lycopersici, momordicae and radicis-cucumerinum; 5 isolates of melonis; 6 isolates of gladioli; 8 isolates of litii; 10 isolates of lactucae; 12 isolates of tracheiphilum; 13 isolates each of cucumerinum and niveum; 32 isolates of cubense, 15 nonpathogenic isolates of $F_{0}$ and 8 isolates of seven different Fusarium spp. (Table 1). Each 25- $\mu \mathrm{l}$ PCR mixture contained $1 \mu \mathrm{l} F_{0}$ DNA, PCR Master Mix (Genemark Technology Co., Ltd., Taiwan) and $0.2 \mu \mathrm{M}$ of each specific primer. PGR amplification was performed under the following temperature cycles: $95^{\circ} \mathrm{C}$ for 
Table 1. Identification code, Fusarium oxysporum forma specialis or source of isolation of other fungal species, geographic origin, pathogenicity test and their results of PCR amplification for each isolate used in this study.

\begin{tabular}{|c|c|c|c|c|c|}
\hline \multirow[t]{2}{*}{ Isolate } & \multirow[t]{2}{*}{$\begin{array}{l}\text { F. oxysporum } \\
\text { f. sp. or others }\end{array}$} & \multirow[t]{2}{*}{$\begin{array}{l}\text { Geographic } \\
\text { Origin }\end{array}$} & \multirow[t]{2}{*}{$\begin{array}{l}\text { Pathogenicity }{ }^{b} \\
\text { host }\end{array}$} & \multicolumn{2}{|c|}{ PCR Primers $^{c}$} \\
\hline & & & & $\begin{array}{l}\text { FIGS11/ } \\
\text { FIGS12 }\end{array}$ & $\begin{array}{l}\text { FIGS11/ } \\
\text { NPIGSR }\end{array}$ \\
\hline Foc100 & cucumerinum & Nantou, Taiwan & +/cucumber & + & - \\
\hline Foc106 & cucumerinum & Pingtung, Taiwan & +/cucumber & + & - \\
\hline Foc151 & cucumerinum & Nantou, Taiwan & +/cucumber & + & - \\
\hline Foc183 & cucumerinum & Chiai, Taiwan & +/cucumber & + & - \\
\hline Foc829 & cucumerinum & Taichung, Taiwan & +/cucumber & + & - \\
\hline ATCC 16416 & cucumerinum & Florida, USA & +/cucumber & + & - \\
\hline ATCC 204369 & radicis-cucumerinum & USA & ND/cucumber & + & - \\
\hline ATCC 204370 & radicis-cucumerinum & USA & ND/cucumber & + & - \\
\hline ATCC 204371 & radicis-cucumerinum & USA & ND/cucumber & + & - \\
\hline ATCC 204372 & radicis-cucumerinum & USA & ND/cucumber & + & - \\
\hline ATCC 204373 & cucumerinum & USA & ND/cucumber & + & - \\
\hline ATCC 204374 & cucumerinum & USA & ND/cucumber & + & - \\
\hline ATCC 204375 & cucumerinum & USA & ND/cucumber & + & - \\
\hline ATCC 204376 & cucumerinum & USA & ND/cucumber & + & - \\
\hline ATCC 204377 & cucumerinum & USA & ND/cucumber & + & - \\
\hline ATCC 204378 & cucumerinum & USA & ND/cucumber & + & - \\
\hline ATCC 204379 & cucumerinum & USA & ND/cucumber & + & - \\
\hline Fob08 & basilici & Taichung,, Taiwan & +/basil & + & - \\
\hline Fob09 & basilici & Taichung,, Taiwan & +/basil & + & - \\
\hline Fob10 & basilici & Taichung," Taiwan & + /basil & + & - \\
\hline Foch 11-28 & chrysanthemi & Changhua, Taiwan & +/garland chrysanthemum & + & - \\
\hline Focb-21 & cubense & Taiwan & +/Banana & + & - \\
\hline Focb-24 & cubense & Taiwan & +/Banana & + & - \\
\hline Focb25 & cubense & Taiwan & +/Banana & + & - \\
\hline Focb-T14 & cubense & Taitung, Taiwan & +/Banana & + & - \\
\hline Focb-T34 & cubense & Taitung, Taiwan & +/Banana & + & - \\
\hline Focb-T35 & cubense & Taitung, Taiwan & +/Banana & + & - \\
\hline Focb-T36 & cubense & Taitung, Taiwan & +/Banana & + & - \\
\hline Focb-T38 & cubense & Taitung, Taiwan & +/Banana & + & - \\
\hline Focb-T44 & cubense & Taitung, Taiwan & +/Banana & + & - \\
\hline Focb-T105 & cubense & Nantou, Taiwan & +/Banana & + & - \\
\hline Focb-132 & cubense & Chiyi, Taiwan & +/Banana & + & - \\
\hline Focb-135 & cubense & Nantou, Taiwan & +/Banana & + & - \\
\hline Focb-136 & cubense & Nantou, Taiwan & +/Banana & + & - \\
\hline Focb-137 & cubense & Pingtung, Taiwan & +/Banana & + & - \\
\hline Focb-138 & cubense & Pingtung, Taiwan & +/Banana & + & - \\
\hline Focb-3-1 & cubense & Pingtung, Taiwan & +/Banana & + & - \\
\hline Focb-3-3 & cubense & Pingtung, Taiwan & +/Banana & + & - \\
\hline Focb-4-2 & cubense & Kaohsiung, Taiwan & +/Banana & + & - \\
\hline Focb-6-2 & cubense & Hualien, Taiwan & +/Banana & + & - \\
\hline Focb-7-7 & cubense & Taitung, Taiwan & +/Banana & + & - \\
\hline Focb-7-9 & cubense & Chiyi, Taiwan & +/Banana & + & - \\
\hline Focb-7-13 & cubense & Nantou, Taiwan & +/Banana & + & - \\
\hline Focb-TN3 & cubense & Kaohsiung, Taiwan & +/Banana & + & - \\
\hline ATCC 38741 & cubense & Taiwan & +/Banana & + & - \\
\hline ATCC 76243 & cubense & SJ. Queensland, Australia & +/Banana & + & - \\
\hline
\end{tabular}


Table 1. Cont.

\begin{tabular}{|c|c|c|c|c|c|}
\hline \multirow[t]{2}{*}{ Isolate } & \multirow[t]{2}{*}{$\begin{array}{l}\text { F. oxysporum } \\
\text { f. sp. or others }\end{array}$} & \multirow[t]{2}{*}{$\begin{array}{l}\text { Geographic } \\
\text { Origin }\end{array}$} & \multirow[t]{2}{*}{$\begin{array}{l}\text { Pathogenicityb/ } \\
\text { host }\end{array}$} & \multicolumn{2}{|c|}{ PCR Primers $^{c}$} \\
\hline & & & & $\begin{array}{l}\text { FIGS11/ } \\
\text { FIGS12 }\end{array}$ & $\begin{array}{l}\text { FIGS11/ } \\
\text { NPIGSR }\end{array}$ \\
\hline ATCC 76247 & cubense & Honduras & +/Banana & + & - \\
\hline ATCC 76257 & cubense & Honduras & +/Banana & + & - \\
\hline ATCC 76262 & cubense & Taiwan & +/Banana & + & - \\
\hline ATCC 96285 & cubense & SE. Queensland, Australia & +/Banana & + & - \\
\hline ATCC 96288 & cubense & N. Queensland, Australia & +/Banana & + & - \\
\hline ATCC 96289 & cubense & SE. Queensland, Australia & +/Banana & + & - \\
\hline ATCC 96290 & cubense & SE. Queensland, Australia & +/Banana & + & - \\
\hline Fog01 & gladioli & Pintung, Taiwan & +/Gladiolus & + & - \\
\hline Fog03 & gladioli & Kaohsung, Taiwan & +/Gladiolus & + & - \\
\hline Fog 050 & gladioli & Pintung, Taiwan & +/Gladiolus & + & - \\
\hline Fog051 & gladioli & Pintung, Taiwan & +/Gladiolus & + & - \\
\hline Fog052 & gladioli & Pintung, Taiwan & +/Gladiolus & + & - \\
\hline Fog053 & gladioli & Pintung, Taiwan & +/Gladiolus & + & - \\
\hline Fola-2 & lactucae & Yunlin, Taiwan & +/lettuce & + & - \\
\hline Fola-18 & lactucae & Yunlin, Taiwan & +/lettuce & + & - \\
\hline Fola-11-13 & lactucae & Yunlin, Taiwan & +/lettuce & + & - \\
\hline Fola-32-14 & lactucae & Yunlin, Taiwan & +/lettuce & + & - \\
\hline Fola 103-7 & lactucae & Yublin, Taiwan & +/lettuce & + & - \\
\hline Fola-106-1 & lactucae & Yunlin, Taiwan & +/lettuce & + & - \\
\hline Fola-106-3 & lactucae & Yunlin, Taiwan & +/lettuce & + & - \\
\hline Fola-10 & lactucae & Taoyuan, Taiwan & +/lettuce & + & - \\
\hline Fola-40 & lactucae & Taoyuan, Taiwan & +/lettuce & + & - \\
\hline ATCC 76616 & lactucae & CA, USA & +/lettuce & + & - \\
\hline Foli G-16 & lilii & Changhua, Taiwan & +/lily & + & - \\
\hline Foli002 & lilii & Nantou, Taiwan & +/lily & + & - \\
\hline Foli016 & lilii & Taichung, Taiwan & +/lily & + & - \\
\hline Foli025 & lilii & Taichung, Taiwan & +/lily & + & - \\
\hline Foli044 & lilii & Taichung, Taiwan & +/lily & + & - \\
\hline Foli046 & lilii & Taichung, Taiwan & + /lily & + & - \\
\hline Foli156 & lilii & Taichung, Taiwan & +/lily & + & - \\
\hline Foli169 & lilii & Taichung, Taiwan & +/lily & + & - \\
\hline Folu114 & luffae & Nantou, Taiwan & +/loofah & + & - \\
\hline Folu638 & luffae & Kaohsiung, Taiwan & +/loofah & + & - \\
\hline FoluDS2 & luffae & Tainan, Taiwan & $+/$ loofah & + & - \\
\hline FoluO1 & luffae & Nantou, Taiwan & +/loofah & + & - \\
\hline Foly11A Race1 & lycopersici & Hualien, Taiwan & +/tomato & + & - \\
\hline Foly34-1 Race2 & lycopersici & Hualien, Taiwan & +/tomato & + & - \\
\hline Foly146 Race2 & lycopersici & Hualien, Taiwan & +/tomato & + & - \\
\hline Foly195 Race1 & lycopersici & Hualien, Taiwan & +/tomato & + & - \\
\hline Fom2 & melonis & Tainan, Taiwan & +/muskmelon & + & - \\
\hline Fom3 & melonis & Tainan, Taiwan & +/muskmelon & + & - \\
\hline Fom4 & melonis & Tainan, Taiwan & -/muskmelon & + & - \\
\hline Fom5 & melonis & Taichung, Taiwan & +/muskmelon & + & - \\
\hline Fom6 & melonis & Taichung, Taiwan & +/muskmelon & + & - \\
\hline Fomo33 & momordicae & Taichung, Taiwan & +/bitter gourd & + & - \\
\hline Fomo34 & momordicae & Taichung, Taiwan & +/bitter gourd & + & - \\
\hline Fomo35 & momordicae & Taichung, Taiwan & +/bitter gourd & + & - \\
\hline
\end{tabular}


Table 1. Cont.

\begin{tabular}{|c|c|c|c|c|c|}
\hline \multirow[t]{2}{*}{ Isolate } & \multirow[t]{2}{*}{$\begin{array}{l}\text { F. oxysporum } \\
\text { f. sp. or others }\end{array}$} & \multirow[t]{2}{*}{$\begin{array}{l}\text { Geographic } \\
\text { Origin }\end{array}$} & \multirow[t]{2}{*}{$\begin{array}{l}\text { Pathogenicityb/ } \\
\text { host }\end{array}$} & \multicolumn{2}{|c|}{ PCR Primers $^{c}$} \\
\hline & & & & $\begin{array}{l}\text { FIGS11/ } \\
\text { FIGS12 }\end{array}$ & $\begin{array}{l}\text { FIGS11/ } \\
\text { NPIGSR }\end{array}$ \\
\hline Fomo36 & momordicae & Taichung, Taiwan & +/bitter gourd & + & - \\
\hline Fon-K0104 & niveum & Tainan, Taiwan & +/watermelon & + & - \\
\hline Fon-K0105 & niveum & Tainan, Taiwan & +/watermelon & + & - \\
\hline Fon-D0201 & niveum & Changhua, Taiwan & +/watermelon & + & - \\
\hline Fon-D0502 & niveum & Changhua, Taiwan & +/watermelon & + & - \\
\hline Fon-D0503 & niveum & Changhua, Taiwan & +/watermelon & + & - \\
\hline Fon-D0604 & niveum & Changhua, Taiwan & +/watermelon & + & - \\
\hline Fon-D0703 & niveum & Changhua, Taiwan & +/watermelon & + & - \\
\hline Fon-H0103 & niveum & Miaoli, Taiwan & +/watermelon & + & - \\
\hline Fon-P0101 & niveum & Nantou, Taiwan & +/watermelon & + & - \\
\hline Fon-P0401 & niveum & Nantou, Taiwan & +/watermelon & + & - \\
\hline ATCC 42006 & niveum & Taiwan & +/watermelon & + & - \\
\hline ATCC 44293 & niveum & California, USA & +/watermelon & + & - \\
\hline ATCC 64104 & niveum & Taiwan & +/watermelon & + & - \\
\hline Fop04 & phaseoli & Nantou, Taiwan & $+/$ snap bean & + & - \\
\hline Fop05 & phaseoli & Nantou, Taiwan & + /snap bean & + & - \\
\hline Fop06 & phaseoli & Nantou, Taiwan & +/snap bean & + & - \\
\hline F54 & tracheiphilum & Pingtung, Taiwan & +/asparagus bean & + & - \\
\hline F55 & tracheiphilum & Pingtung, Taiwan & +/asparagus bean & + & - \\
\hline F67 & tracheiphilum & Taichung, Taiwan & +/asparagus bean & + & - \\
\hline F74 & tracheiphilum & USA. & +/asparagus bean & + & - \\
\hline F75 & tracheiphilum & USA. & +/asparagus bean & + & - \\
\hline F80 & tracheiphilum & USA. & +/asparagus bean & + & - \\
\hline F85 & tracheiphilum & USA. & +/asparagus bean & + & - \\
\hline F95 & tracheiphilum & Pingtung, Taiwan & +/asparagus bean & + & - \\
\hline F97 & tracheiphilum & Pingtung, Taiwan & +/asparagus bean & + & - \\
\hline F99 & tracheiphilum & Pingtung, Taiwan & +/asparagus bean & + & - \\
\hline F101 & tracheiphilum & Pingtung, Taiwan & +/asparagus bean & + & - \\
\hline Fot60 & tracheiphilum & Pingtung, Taiwan & +/asparagus bean & + & - \\
\hline Fo276 & F. oxysporum & Hualien, Taiwan & -/cucumber & + & + \\
\hline Fo366 & F. oxysporum & Hualien, Taiwan & -/cucumber & + & + \\
\hline Fo95020 & F. oxysporum & Taichung, Taiwan & -/cucumber & + & - \\
\hline Fo95021 & F. oxysporum & Taichung, Taiwan & -/cucumber & + & - \\
\hline Fo95022 & F. oxysporum & Taichung, Taiwan & -/cucumber & + & + \\
\hline Fo95024 & F. oxysporum & Nantou, Taiwan & -/cucumber & + & + \\
\hline Fo95026 & F. oxysporum & Hualien, Taiwan & -/cucumber & + & + \\
\hline AV-006 & F. oxysporum & Kaohsiung, Taiwan & -/tomato & + & - \\
\hline AV- 007 & F. oxysporum & Ilan, Taiwan & -/tomato & + & - \\
\hline AV-010 & F. oxysporum & Nantou, Taiwan & -/tomato & + & - \\
\hline AV-011 & F. oxysporum & Tainan, Taiwan & -/tomato & + & - \\
\hline AV- 012 & F. oxysporum & Ilan, Taiwan & -/tomato & + & - \\
\hline AV-013-1 & F. oxysporum & Nantou, Taiwan & -/tomato & + & - \\
\hline AV-013-2 & F. oxysporum & Nantou, Taiwan & -/tomato & + & - \\
\hline AV-014 & F. oxysporum & Kaohsiung, Taiwan & -/tomato & + & - \\
\hline SJ2a & F. solani & Chiayi, Taiwan & +/orchid & + & - \\
\hline 939229-3 & F. verticillioides & Yunlin, Taiwan & +/orchid & + & - \\
\hline STP-01 & F. monilion & Taiwan & ND/corn feed & + & - \\
\hline
\end{tabular}


Table 1. Cont.

\begin{tabular}{|c|c|c|c|c|c|}
\hline \multirow[t]{2}{*}{ Isolate } & \multirow[t]{2}{*}{$\begin{array}{l}\text { F. oxysporum } \\
\text { f. sp. or others }\end{array}$} & \multirow[t]{2}{*}{$\begin{array}{l}\text { Geographic } \\
\text { Origin }\end{array}$} & \multirow[t]{2}{*}{$\begin{array}{l}\text { Pathogenicityb/ } \\
\text { host }\end{array}$} & \multicolumn{2}{|c|}{ PCR Primers $^{c}$} \\
\hline & & & & $\begin{array}{l}\text { FIGS11/ } \\
\text { FIGS12 }\end{array}$ & $\begin{array}{l}\text { FIGS11/ } \\
\text { NPIGSR }\end{array}$ \\
\hline Fu3 & F. equiseti & Taiwan & ND & + & - \\
\hline Fu7 & F. decemcellulare & Taiwan & ND & + & - \\
\hline Fu11 & F. concentricum & Taiwan & ND & + & - \\
\hline YPES2 & F. proliferatum & Chiayi, Taiwan & +/orchid & + & - \\
\hline $176-3$ & F. proliferatum & Yunlin, Taiwan & +/orchid & + & - \\
\hline
\end{tabular}

a Pathogenic strains of Fusarium oxysporum were isolated from soil, seed, or diseased host tissue. The other $F$. oxysporum strains were isolated from soil or healthy plant tissue.

${ }^{\mathrm{b}}$ F. oxysporum isolates were tested for their pathogenicity using the root dip assay on their respective hosts, and the symbol " + " means positive for pathogenicity; " $-{ }^{\prime \prime}$ means no disease; "ND" means not tested.

'The symbol " + " means the PCR product of the expected size obtained; "-" means no PCR product of the expected size obtained.

doi:10.1371/journal.pone.0065093.t001

Table 2. The reference isolates used for phylogenetic analysis in this study.

\begin{tabular}{|c|c|c|c|c|}
\hline \multirow[t]{2}{*}{ NRRL no. } & \multirow[t]{2}{*}{ Host/substrate } & \multirow{2}{*}{ Species/forma specialis } & \multicolumn{2}{|c|}{ Accession no. } \\
\hline & & & EF-1 & IGS \\
\hline 22519 & Cucumis melo & F. oxysporum f. sp. melonis & FJ985266 & FJ985448 \\
\hline 22553 & Raphanus sativus & F. oxysporum f. sp. raphani & FJ985273 & FJ985463 \\
\hline 22554 & Chrysanthemum sp. & F. oxysporum f. sp. tracheiphilum & FJ985274 & FJ985464 \\
\hline 25375 & Human & F. oxysporum & AY527521 & FJ985470 \\
\hline 25378 & Human & F. oxysporum & AY527428 & AY527624 \\
\hline 25387 & Human & F. oxysporum & AY527527 & FJ985471 \\
\hline 25594 & Ipomoea batatas & F. oxysporum f. sp. batatas & AY337717 & FJ985478 \\
\hline 26024 & Musa & F. oxysporum & AY527535 & AY527732 \\
\hline 26203 & Solanum esculentum & F. oxysporum f. sp. lycopersici & AF008501 & FJ985487 \\
\hline 26360 & Human eye & F. oxysporum & AY527522 & AY527719 \\
\hline 26363 & Human peritoneal fluid & F. oxysporum & AY527434 & AY527630 \\
\hline 26367 & Human & F. oxysporum & AY527529 & AY527726 \\
\hline 26374 & Human & F. oxysporum & AF008483 & AY527714 \\
\hline 26413 & Momordica charantia & F. oxysporum f. sp. momordicae & FJ985291 & FJ985498 \\
\hline 26679 & Human & F. oxysporum & AY527526 & AY527723 \\
\hline 28031 & Human & F. oxysporum & AY527523 & AY527720 \\
\hline 28687 & Human & F. oxysporum & AY527525 & AY527722 \\
\hline 32958 & Human & F. oxysporum & AY527504 & AY527700 \\
\hline 36110 & Musa 'Cavendish' & F. oxysporum f. sp. cubense & FJ985327 & FJ985560 \\
\hline 36114 & Musa 'Pisang Manurung' & F. oxysporum f. sp. cubense & FJ985328 & FJ985561 \\
\hline 36276 & Pisum sativum & F. oxysporum f. sp. pisi & FJ985341 & FJ985574 \\
\hline 36389 & Ipomoea batatas & F. oxysporum f. sp. batatas & FJ985352 & FJ985585 \\
\hline 36464 & Solanum esculentum & F. oxysporum f. sp. lycopersici & FJ985355 & FJ985588 \\
\hline 36472 & Cucumis melo & F. oxysporum f. sp. melonis & FJ985357 & FJ985590 \\
\hline 37616 & Pisum sativum & F. oxysporum f. sp. pisi & FJ985359 & FJ985592 \\
\hline 38289 & Ipomoea batatas & F. oxysporum f. sp. batatas & FJ985368 & FJ985601 \\
\hline 38318 & Ocimum basilicum & F. oxysporum f. sp. basilici & FJ985381 & FJ985615 \\
\hline 38552 & Citrullus lanatus & F. oxysporum f. sp. niveum & FJ985410 & FJ985645 \\
\hline 38591 & Cucumis sativus & F. oxysporum f. sp. cucumerinum & FJ985379 & FJ985613 \\
\hline 31852 & Begonia elatior & F. foetens (outgroup) & HM057337 & HM057282 \\
\hline 38302 & Pinus radiata seedling & F. foetens (outgroup) & GU170559 & GU170581 \\
\hline
\end{tabular}

doi:10.1371/journal.pone.0065093.t002 


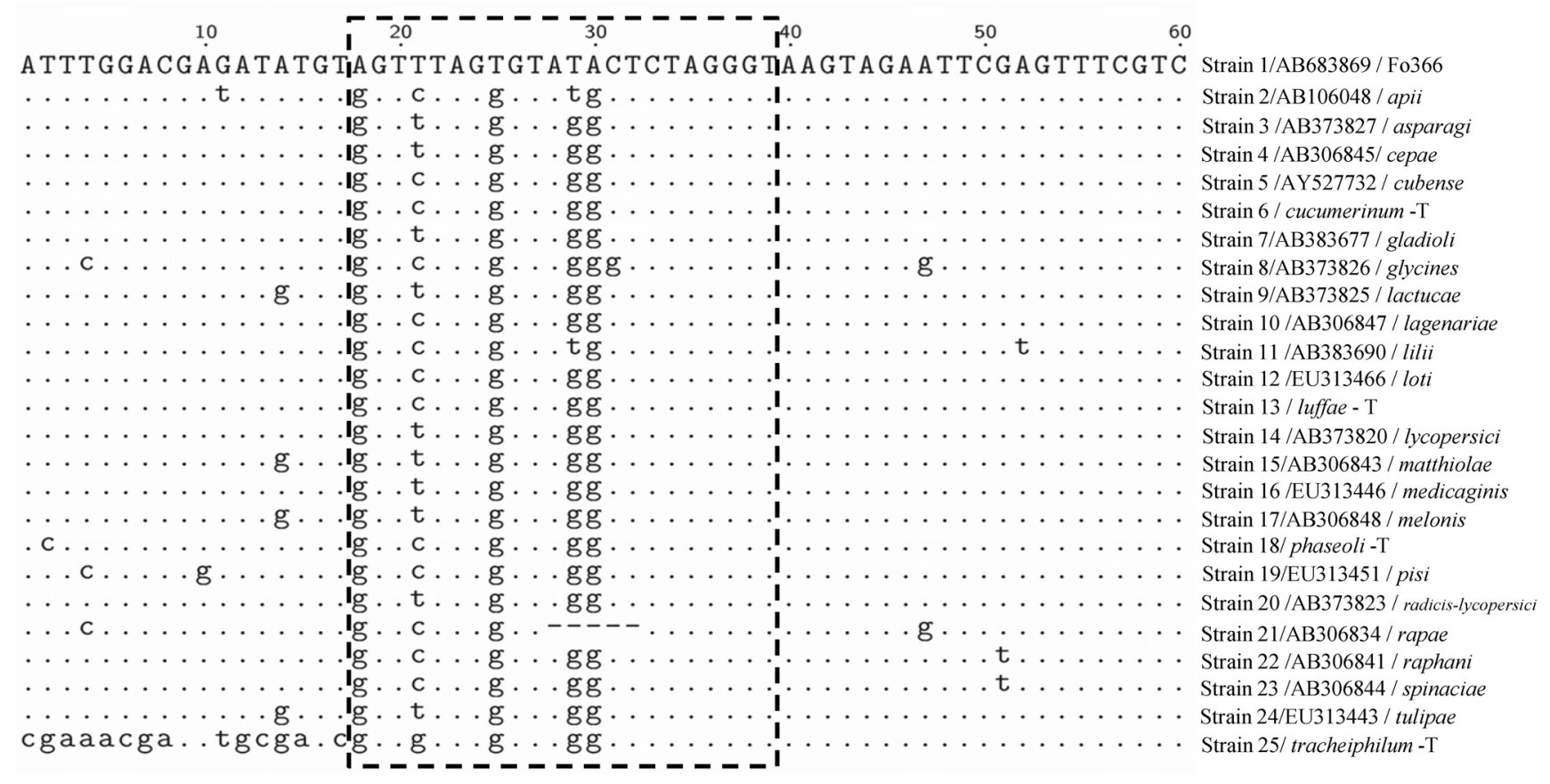

Figure 1. Nucleotide variation of nonpathogenic Fo isolates (Fo366) and other Fo formae speciales. Nucleotide sequence alignment of the rDNA repeats encoding a part of the intergenic spacer region (IGS) for strains of nonpathogenic Fusarium oxysporum (strain 1: Fo366) and pathogenic $F$. oxysporum of 24 formae speciales strains (strains 2-25 represented apii, asparagi, cepae, cubense, cucumerinum-T, gladioli, glycines, lactucae, lagenariae, lilii, loti, luffae-T, lycopersici, matthiolae, medicaginis, melonis, phaseoli-T, pisi, radicis-lycopersici, rapae, raphani, spinaciae, tulipae and tracheiphilum-T, respectively. The notation -T stand for the strains that were isolated from samples collected from Taiwan). The nucleotide bases in the Fo366 sequences different from the other 24 formae speciles are indicated below the sequences. Lowercase letters indicate the nucleotide bases that differ between the pathogenic and the (Fo366) nonpathogenic strains. The dashes indicate base gaps. The dashed line region represented the sequence of specific primer, NPIGS-R.

doi:10.1371/journal.pone.0065093.g001

$2 \mathrm{~min}$, followed by 30 cycles of denaturing at $95^{\circ} \mathrm{C}$ for $30 \mathrm{sec}$, annealing at $58^{\circ} \mathrm{C}$ fo $\mathrm{r} 1 \mathrm{~min}$, and polymerizing at $72^{\circ} \mathrm{C}$ for $45 \mathrm{sec}$, and then a final extension at $72^{\circ} \mathrm{C}$ for 10 min. PCR products were subjected to electrophoresis in $1.5 \%$ agarose gels.

To evaluate the sensitivity of the test, the quality of Fo276 DNA was quantified in GeneQuant 100 classic spectrophotometer (GE Healtcare), and diluted into several concentrations from 200 to $10^{-}$ ${ }^{3}$ ng using $1 \mu \mathrm{l}$ of each concentration in each treatment as template DNA in a $25-\mu \mathrm{l}$ PCR reaction volume. The sensitivity experiments were replicated three times with independent dilutions. Isolate Fo276 was used instead of Fo366 as a nonpathogenic $F_{0}$ type strain because it shared $100 \%$ similarity in nucleotide sequence identity with Fo366 and because isolate Fo366 started to show a decrease in its capacity to control Fusarium wilt over the course of this study (Wang, unpublished data).

To detect the fungal colonization of cucumber roots by nonpathogenic $F_{0}$ isolates, three cucumber seeds (Showy Green, Known-You seed Co., Ltd, Taiwan) were sown into three $5 \mathrm{~cm} \times$ $5 \mathrm{~cm}$ plastic tray cells containing infested peat moss $\left(2 \times 10^{6}\right.$ conidia/g) for each nonpathogenic isolate. Conidia were produced on 2- to 3-wk-old PDA plate cultures at $28^{\circ} \mathrm{C}$. Conidia were washed from the plates with sterile water, filtered through Miracloth (Calbiochem, San Diego, CA, USA), and quantified by counting in an improved Neubauer bright-line counting chamber (Marienfeld, Germany). One week after sowing, root tissues were collected from the seedlings, and total genomic DNA was extracted using the Plant Genomic DNA Purification Kit (Genemark Technology Co., Ltd, Taiwan) and used as template DNA.
For the detection of Fo276 in soil, a $1.5 \times 10^{4}$ conidia/ml suspension was prepared from PDA plate cultures, as described above, and diluted in 10-fold increments to obtain a series of conidial concentrations. One milliliter of each concentration was added to microtubes containing one gram of autoclaved soil to establish various concentrations from 150,000 to 150 conidia/g soil. Total genomic DNA from each treatment was extracted using the Soil Genomic DNA Purification Kit (Genemark Technology Co., Ltd, Taiwan). All the PCR reactions were conducted three times to confirm reproducibility.

\section{Evaluation of Biocontrol Potential of Nonpathogenic Fo Isolates}

Inoculum for infesting soil in pots with the pathogenic Foc isolate (Foc100) was produced on an oat/sand medium [31]. The propagation medium (200 g oats, $200 \mathrm{~g}$ sand, and $400 \mathrm{ml}$ distilled water), contained in 1-L flasks, was autoclaved for $20 \mathrm{~min}$ on two consecutive days. Twenty $\mathrm{ml}$ of a $1 \times 10^{6}$ spores $/ \mathrm{ml}$ suspension collected from PDA plate cultures were aseptically pipetted into each culture flask, which was then incubated for 2-3 wk at room temperature to allow for colonization. Subsequently, the contents of the culture flasks were air dried for $1 \mathrm{wk}$ and triturated into a fine powder using a blender (RT-04, Rong Tsong Precision Technology Co., Taiwan). Dry inoculum was mixed with nonsterilized (shown to be Foc-free) Taichung field soil to achieve an inoculum level of $10^{3}$ propagules/g of dry soil, as determined by 10 -fold serial dilution plating on PCNB medium.

To evaluate the potential of nonpathogenic $F_{0}$ isolates in reducing the severity of Fusarium wilt of cucumber, 10 susceptible 


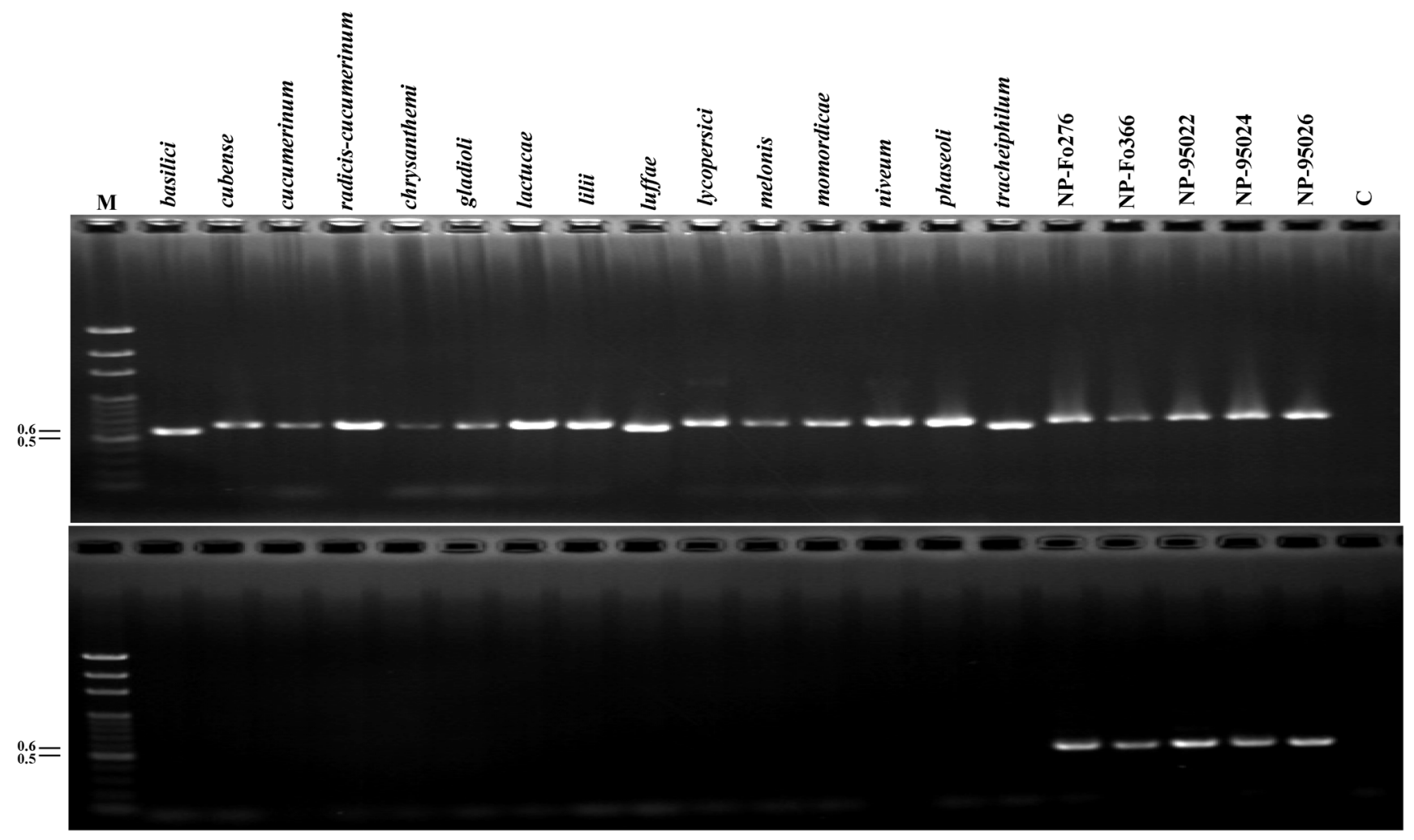

Figure 2. Specificity of the modified primer pair. Agarose gels showing the amplification products from polymerase chain reaction (PCR) using genomic DNA from isolates of 15 formae speciales, including basilici, chrysanthemi, cubense, cucumerinum, radicis-cucumerinum, gladioli, lactucae, lilii, luffae, lycopersici, melonis, momordicae, niveum, phaseoli and tracheiphilum, and five nonpathogenic strains of Fusarium oxysporum (Fo). (A) 550 to $650 \mathrm{bp}$ DNA products of different formae speciles and nonpathogenic Fo isolates amplified by FIGS11/FIGS12. (B) 500-bp DNA product of five nonpathogenic Fo isolates amplified by new primer NPIGS-R and FIGS11. The numbers on the left are the molecular weights (Kb) of the Gen-100 bp DNA ladder (GeneMark) (lane M). doi:10.1371/journal.pone.0065093.g002

plants (Showy Green, Known-You seed Co., Ltd, Taiwan) per isolate were grown in $5 \mathrm{~cm} \times 5 \mathrm{~cm}$ cell plastic trays containing noninfested peat moss or peat moss infested with conidia from nonpathogenic isolates as described in the previous section of this paper. Trays were seeded and held in the greenhouse for 10-14 days, at which time the seedlings were transplanted into $12.5 \mathrm{~cm}$ diameter pots containing either noninfested or Foc100-infested field soil with $10^{3}$ propagules/g of dry soil. These plants were incubated for $8 \mathrm{wk}$ in a greenhouse at $25-35^{\circ} \mathrm{C}$ and observed for symptom development. Disease severity was assessed weekly on a 0 -4 scale in which " 0 " = healthy plants, " $1 "=$ plants with yellowing of the cotyledons and the first leaf, " 2 " = stunted plants or yellowing of less than half of the leaves, " 3 " = plants with stem yellowing, vascular discoloration and wilting of more than half of the leaves, and " 4 " = plants completely wilted or dead. The disease severity for each replicate of each treatment was calculated by the following formula: $\left(\Sigma \mathrm{S}_{\mathrm{i}} \times \mathrm{N}_{\mathrm{i}}\right) \times 100 /\left(4 \times \mathrm{N}_{\mathrm{t}}\right)$, where $\mathrm{Si}$ is the severity ratings 0 to $4, \mathrm{~N}_{\mathrm{i}}$ is the number of plants in each rating, and $\mathrm{N}_{\mathrm{t}}$ is the total number of rated plants.

\section{Use of FIGS11/NPIGS-R to Identify Fo Isolates with Biocontrol Potential}

Seventy-seven $F_{0}$ isolates, 63 from soil and 14 from plant tissues, were collected at various locations across Taiwan and evaluated by PCR using the FIGS11/NPIGS-R primer set for amplification of the 500-bp IGS fragment. Isolates that tested positive for amplification were tested for pathogenicity to cucumber seedlings in a greenhouse root dip-inoculation test (5) and for their potential to suppress Fusarium wilt development using the method described in the preceding section.

\section{Phylogenetic Analysis of Nonpathogenic Fo Showing Efficacy on Control Cucumber Wilting Based on EF-1 $\alpha$ Gene and IGS Region}

Previous studies indicated that $F$. oxysporum might be an opportunistic pathogen of human [32], [33]. For realizing the relationship between nonpathogenic $F_{0}$ with biocontrol activity and the pathogenic $F_{0}$ of human and plant, two DNA regions of translation elongation factor $(\mathrm{EF}-1 \alpha)$ gene and intergenic spacer (IGS) were used to amplify and analyze following the method reported by O'Donell et al. [33]. The primers for amplifying EF$1 \alpha$ gene and IGS were EF-1H (5' -ATGGGTAAGGAAGACAAGAC - 3')/EF-2T (5' -GGAAGTAGCAGTGATCATGTT- 3') and CNS1 (5'-GAGACAAGCATATGACTACTG - 3')/CNL12 (5' -CTGAACGCGTCTAAGTCAG - 3'), respectively [34]. The amplified sequences were aligned by CLUSTAL X 1.8 [35], and further visual alignments were done in SEQUENCE ALIGNMENT EDITOR (Se-Al) v.2.0 [36]. In this study, 11 and 18 isolates of the pathogenic $F_{0}$ from human and plant respectively were used for analysis. Moreover, two isolates $F$. foetens were used as outgroups. The isolate number, species, host and accession no. in GenBank database of these added $F_{0}$ isolates were showed in Table 2. Phylogenetic analysis of the aligned sequences was done by distanced methods. The distance matrix for the aligned 


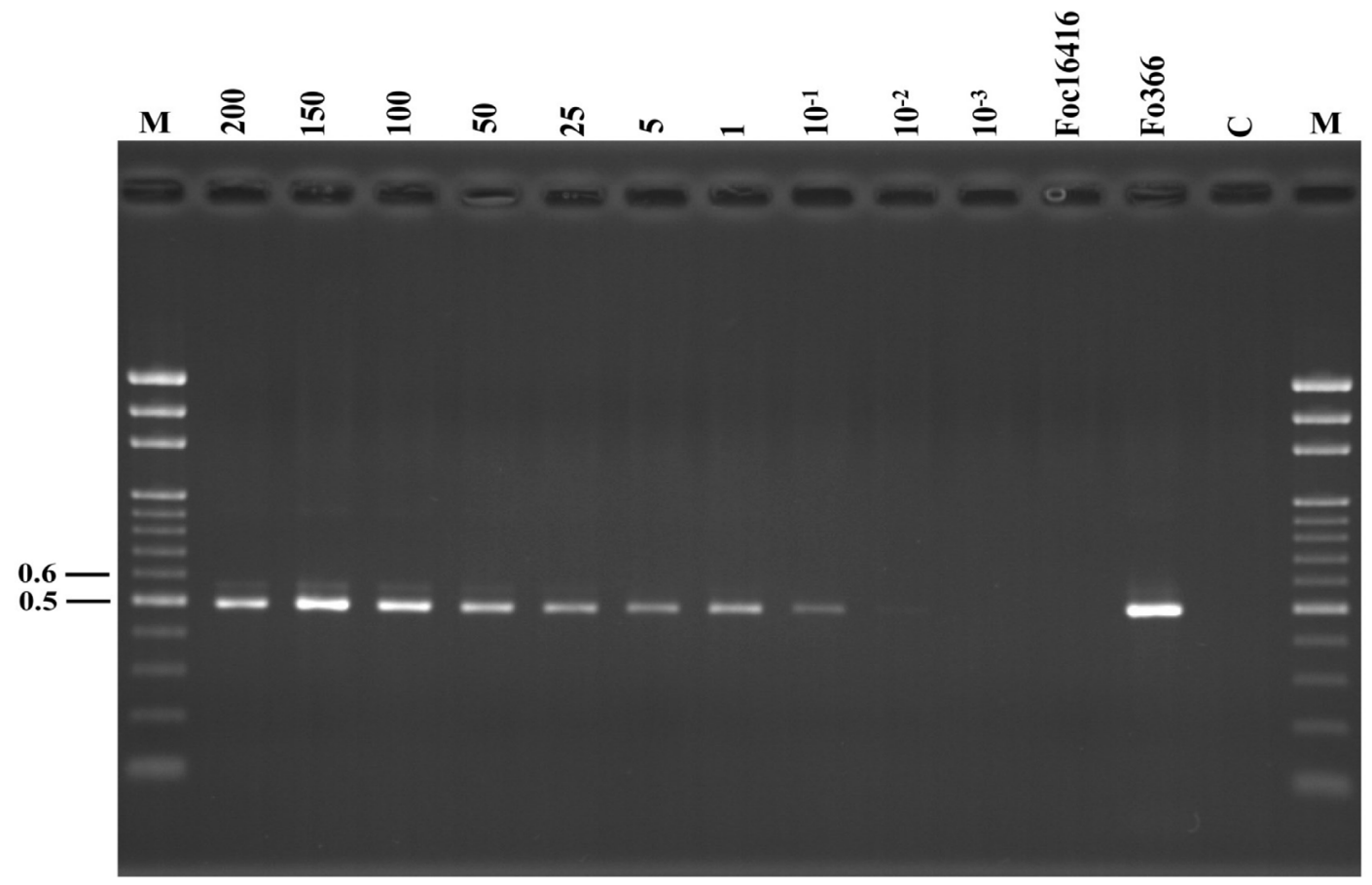

Figure 3. Sensitivity of the newly designed primer. Agarose gel showing the sensitivity of polymerase chain reaction (PCR) using the genomic DNA of a nonpathogenic strain of Fusarium oxysporum and the primer pair FIGS11/NPIGS-R: Amplification of a decreasing amount of the nonpathogenic isolate Fo276 DNA ranging from 200 to $10^{-3} \mathrm{ng}$. The numbers on the left correspond to the molecular weight (kb) of the Gen-100 ladder (lane M). Lanes Foc16416 and Fo366, the amplification controls for the pathogenic isolate of $F$. oxysporum f. sp. cucumerinum (Foc100) and nonpathogenic isolate Fo366 DNA, respectively. Lane C, control reaction with no template DNA.

doi:10.1371/journal.pone.0065093.g003

(A)

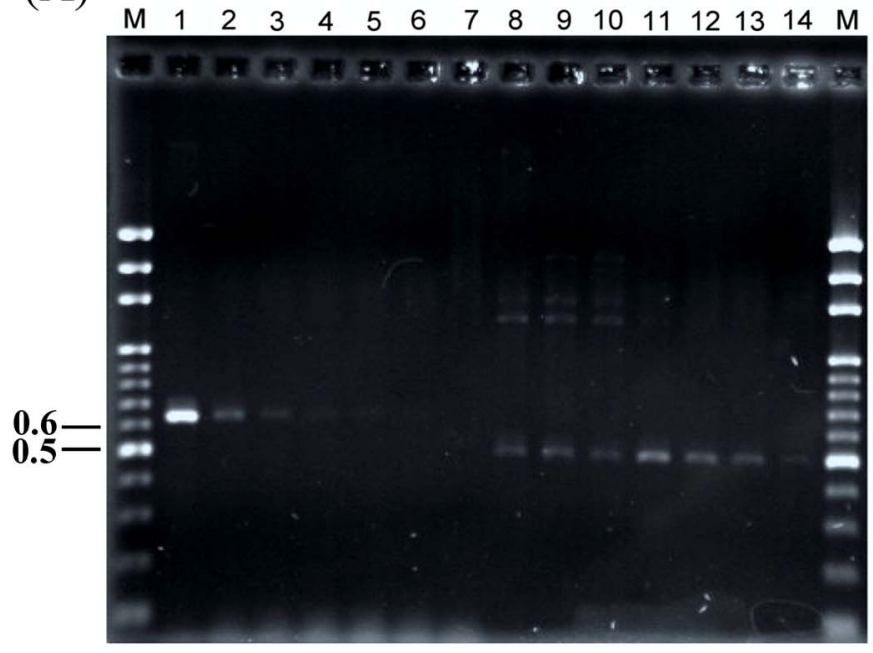

(B)

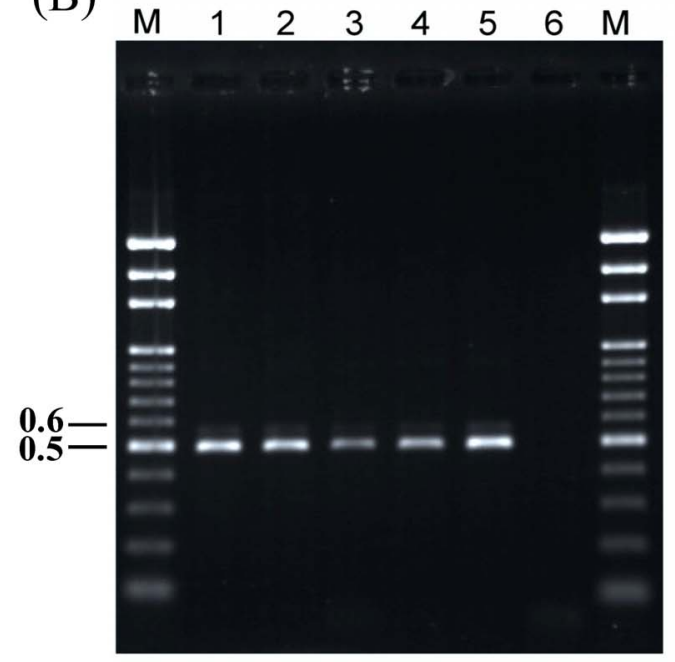

Figure 4. Application of the newly designed primer. The detection sensitivity of the primer sets FIGS11/FIGS12 and FIG11/NPIGS-R amplified DNA fragments of the nonpathogenic Fusarium oxysporum strain Fo276 in plant tissues (A) and soil particles (B). (A): The total genomic DNA of plant root tissues was diluted into different fold dilutions $(1,10,20,40,80,100$ and 200) (lanes 1 to 7 and lanes 8 to 14, respectively), and PCR was performed on these samples with different primer sets. The primers FIGS11 and FIGS12 were used on the samples in lanes 1 to 7 and amplified a 650bp product. Lanes 8 to 14 represented PCR products obtained using the primers FIGS11 and NPIGS-R, which amplified a 500-bp product from total genomic DNA. The numbers on the left are the molecular weights (Kb) of the Gen-100 bp DNA ladder (GeneMark) (lane M). (B): The macro- and microspores of Fo276 were added into soil particles with serial 10 -fold dilutions to generate different spore concentrations ranging from 150,000 to 150 spores/g soil. The primers FIGS11 and NPIGS-R on lane 1 to 5 were able to amplify a 500-bp product from Fo276. The lane corresponded to the following treatments: Lanes 1 to 4 represented soil particles that contained 150,000, 15,000, 1,500 and 150 spores/g soil, respectively. Lane 5 used Fo276 genomic DNA $(100 \mathrm{ng} / \mu \mathrm{l})$ as a positive control. Lane 6 represented sterile $\mathrm{dH}_{2} \mathrm{O}$ added into the soil particles as a negative control. doi:10.1371/journal.pone.0065093.g004 
Table 3. Efficacy of nonpathogenic Fusarium oxysporum isolates to suppress cucumber Fusarium wilt development ${ }^{\mathrm{a}}$.

\begin{tabular}{|c|c|c|c|c|c|c|c|}
\hline \multirow[t]{2}{*}{$\begin{array}{l}\text { Pre-inoculation } \\
\text { treatment }\end{array}$} & \multirow[t]{2}{*}{$\begin{array}{l}\text { PCR } 500-b^{b}{ }^{b} \\
\text { product }\end{array}$} & \multicolumn{6}{|c|}{ Disease severity (\%) ${ }^{c}$ after Fo cucumerinum inoculation } \\
\hline & & $3 \mathbf{w k}$ & 4 wk & $5 \mathrm{wk}$ & $6 \mathrm{wk}$ & $7 \mathrm{wk}$ & $8 \mathbf{w k}$ \\
\hline Water (CK) & NA & 0 & 7 & $25 \mathrm{~b}$ & $43 b$ & $57 \mathrm{~b}$ & $71 c$ \\
\hline 95020 & - & 0 & 0 & $57 c$ & $39 \mathrm{~b}$ & $57 \mathrm{~b}$ & $71 c$ \\
\hline 95021 & - & 0 & 0 & $14 a b$ & $57 \mathrm{~b}$ & $68 \mathrm{~b}$ & $71 c$ \\
\hline 95022 & + & 0 & 0 & $0 a$ & $7 a$ & $57 \mathrm{~b}$ & $96 c$ \\
\hline 95024 & + & 0 & 0 & 0a & $0 a$ & 0a & $14 a$ \\
\hline 95026 & + & 0 & 0 & 0a & 0a & $14 a$ & $43 b$ \\
\hline Fo276 & + & 0 & 0 & 0a & $6 a$ & $6 a$ & $6 a$ \\
\hline Fo366 & + & 0 & 10 & $21 \mathrm{~b}$ & $25 \mathrm{~b}$ & $40 \mathrm{~b}$ & $44 b$ \\
\hline
\end{tabular}

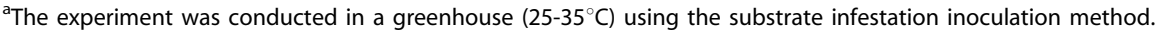

bPlants of each treatment were assayed on a scale of 0-4:0 = Healthy plants, $1=$ cotyledon and first leaf with yellowing, $2=$ stunting or $<1 / 2$ leaves with yellowing, $3=$ stem yellowing, vascular discoloration, and $>1 / 2$ leaves with wilt symptoms, and $4=$ plant wilted or dead. The disease scale was converted to disease severity and rounded off, as described in the Materials and Methods.

'Amplification by primer pair FIGS11/NPIGS-R; NA = not applicable, - = not. amplified, $+=$ amplified.

doi:10.1371/journal.pone.0065093.t003

sequences was calculated with the neighbor-joining $(\mathrm{NJ})$ method [37]. Reliability of the inferred trees was estimated by 1,000 bootstrap resampling using the same program. Bootstrap [38] values were generated with 1,000 replicate heuristic searches to estimate support for clade stability of the consensus tree using the same program.

\section{Statistical Analyses}

Data were analyzed with the software SPSS 10.0 for Windows ${ }^{\circledR}$ (LEAD Technologies, Inc., Charlotte, NC, USA). ANOVA was performed, and the Duncan post-hoc test was conducted to assess the differences among the treatments within each week at $\mathrm{p}=0.05$.

\section{Results}

\section{Primer Design}

Amplified fragments of nonpathogenic $F_{0}$ isolate Fo366 (strain

1) and four pathogenic $F_{0}$ isolates (strains 6, 13, 18 and 25) were purified, sequenced and then compared for nucleotide variation with 20 other $F_{0}$ formae speciales using Clustal X 1.81 alignment software (Fig 1). The specific primer NPIGS-R (5' - ACCCTAGAGTATACACTAAACT - 3') was designed according to the polymorphisms found in the IGS DNA sequence of Fo366 when compared with the formae speciales isolates (Fig 1).

\section{Specificity of the Modified Primer Pair}

The newly designed primer NPIGS-R combined with FIGS11 was used to assess the amplification of 122 formae speciales isolates, eight different Fusarium spp. isolates and 15 nonpathogenic $F_{0}$ isolates. No fragment or expected size was amplified from the 122 pathogenic $F_{0}$ and 8 different Fusarium spp. isolates (Table 1). A 500-bp fragment was amplified from the $F_{0}$ isolates Fo95022, Fo95024, Fo95026, Fo276 and Fo366, but no PCR product was amplified from other $F_{0}$ isolates (Table 1). The PCR-amplified fragments of the $F_{0}$ isolates Fo95022, Fo95024, Fo95026, and Fo276 were sequenced, and the nucleotide sequences showed

Table 4. Pathogenicity evaluation of the six Fo isolates that were PCR positive using the primers FIGS11 and NPIGS-R.

\begin{tabular}{|c|c|c|c|c|}
\hline Isolate & $\begin{array}{l}\text { Fungal } \\
\text { species }\end{array}$ & $\begin{array}{l}\text { Isolation } \\
\text { sources }\end{array}$ & $\begin{array}{l}P C R^{a} \\
\text { amplification }\end{array}$ & $\begin{array}{l}\text { Pathogenic to } \\
\text { cucumber }^{\text {b }}\end{array}$ \\
\hline Fo7 & Fusarium oxysporum & Wax apple & + & - \\
\hline HS33 & Fusarium oxysporum & Suppressive Soil & + & - \\
\hline OSS11 & Fusarium oxysporum & Rhizosphere Soil & + & - \\
\hline OSS12 & Fusarium oxysporum & Rhizosphere Soil & + & - \\
\hline OSS14 & Fusarium oxysporum & Rhizosphere Soil & + & - \\
\hline SPA7 & Fusarium oxysporum & Sweet potato & + & - \\
\hline Foc100 & Fusarium oxysporum & cucumber & - & + \\
\hline Fol146 & ??????????????????? & tomato & - & - \\
\hline
\end{tabular}


Table 5. Biocontrol efficacy of the six Fusarium oxysporum isolates shown to be nonpathogenic to cucumber ${ }^{\mathrm{a}}$.

\begin{tabular}{|c|c|c|c|c|}
\hline \multirow{2}{*}{$\begin{array}{l}\text { Pre-inoculation } \\
\text { treatment }\end{array}$} & \multicolumn{4}{|c|}{ Disease severity $(\%)^{\mathbf{b}}$ after Fo cucumerinum inoculation } \\
\hline & $5 \mathrm{wk}$ & $6 \mathrm{wk}$ & $7 \mathrm{wk}$ & $8 \mathrm{wk}$ \\
\hline Water $(\mathrm{CK})^{\mathrm{c}}$ & 16 & 27 & $55 a$ & $63 a$ \\
\hline Fo276 & 9 & 11 & $16 \mathrm{~b}$ & $21 b$ \\
\hline SPA7 & 2 & 4 & $13 \mathrm{~b}$ & $25 \mathrm{~b}$ \\
\hline Fo7 & 5 & 5 & $11 \mathrm{~b}$ & $11 \mathrm{~b}$ \\
\hline OSS11 & 7 & 13 & $20 \mathrm{~b}$ & $23 b$ \\
\hline OSS12 & 9 & 11 & $16 \mathrm{~b}$ & $21 \mathrm{~b}$ \\
\hline OSS14 & 0 & 0 & $7 \mathrm{~b}$ & $9 \mathrm{~b}$ \\
\hline HS33 & 3 & 8 & $8 b$ & $25 b$ \\
\hline
\end{tabular}

aThe experiment was conducted in a greenhouse $\left(18-28^{\circ} \mathrm{C}\right)$ using the substrate infestation inoculation method.

${ }^{\mathrm{b}}$ Plants of each treatment were assayed on a scale of $0-4: 0=$ Healthy plants, $1=$ cotyledon and first leaf with yellowing, $2=$ stunting or $<1 / 2$ leaves with yellowing, $3=$ stem yellowing, vascular discoloration, and $>1 / 2$ leaves with wilt symptoms, and $4=$ plant wilted or dead. The disease scale was converted to disease severity and rounded off, as described in the Materials and Methods.

'The CK treatment was pre-inoculated with distilled water and then transplanted into infested soil with Foc100.

doi:10.1371/journal.pone.0065093.t005

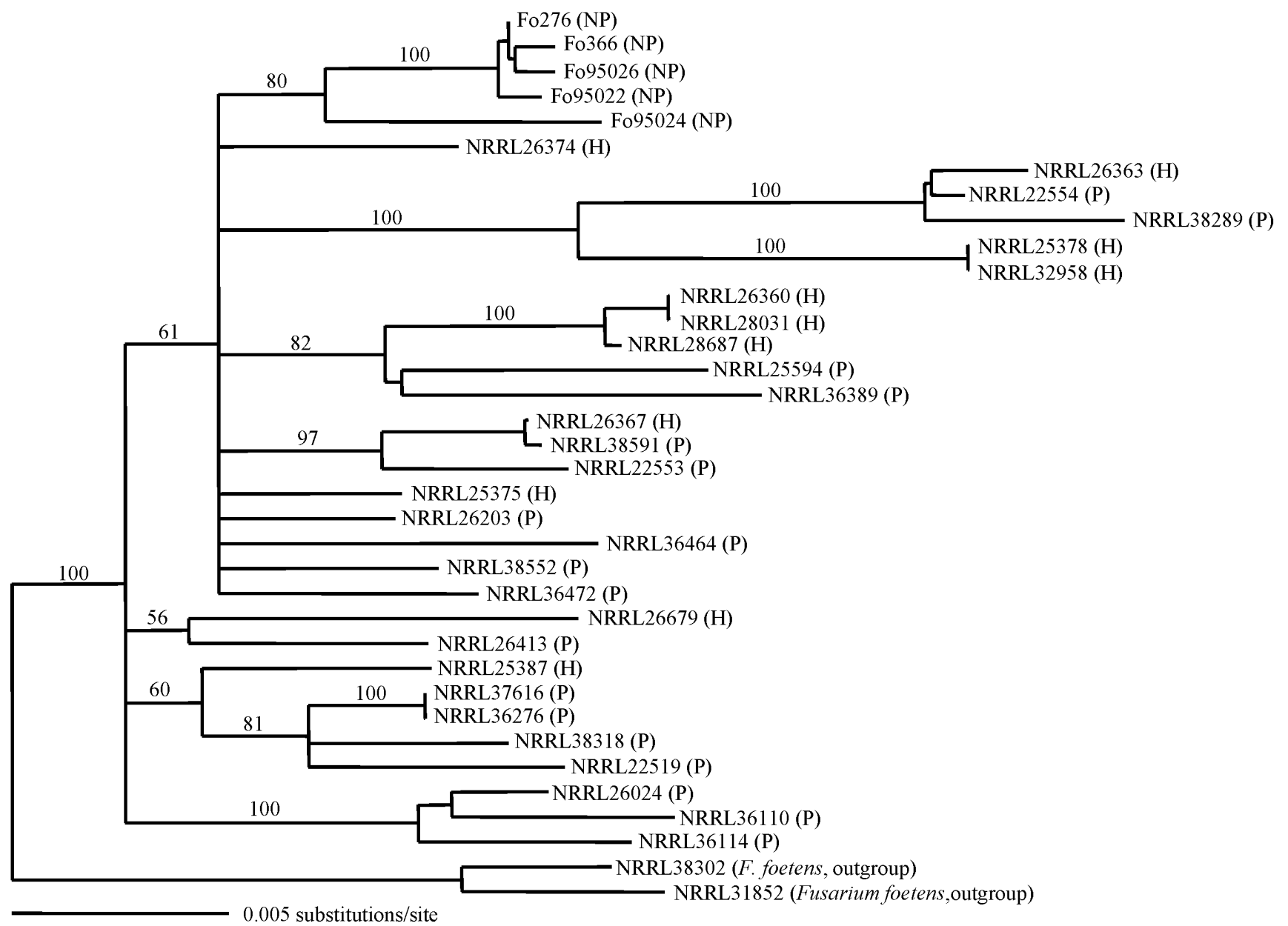

Figure 5. EF-1 $\alpha$ and IGS sequence-based tree generated with neighbour-joining analysis. Numbers at branch modes indicate reliable values from bootstrap analysis with 1000 replications. Fusarium foetens NRRL38302 and 31852 were used as outgroups to root the tree. $\mathrm{NP}=$ nonpathogenic Fusarium oxysporum with biological control activity; $\mathrm{H}=$ Human pathogen; $\mathrm{P}=\mathrm{Plant}$ pathogen.

doi:10.1371/journal.pone.0065093.g005 
100\% identity with Fo366. In contrast, all isolates, both pathogenic, nonpathogenic and different Fusarium spp., had a 550 to 700-bp fragment amplified using the primer pair FIGS11/ FIGS12, thereby confirming the quality of the genomic DNA and the species of $F$. oxysporum. The electrophoresis picture of PCR reactions of partial F. oxysporum isolates was showed in Fig 2.

\section{Sensitivity and Application of the Newly Designed Primer}

The results of the PCR sensitivity test showed that the primers FIGS 11 and NPIGS-R could amplify the 500-bp fragment from as little as $10 \mathrm{pg}\left(10^{-2} \mathrm{ng}\right)$ template DNA in a $25-\mu$ l reaction mixture (Fig 3). The utility of these primers to detect nonpathogenic $F_{0}$ in roots was shown by the detection of Fo276 in roots of artificially infected cucumber seedlings. A PCR product was obtained with extracted DNA down to a 200-fold dilution. In contrast, with the FIGS11/FIGS12 primer pair, PGR products were only obtained down to an 80-fold dilution. The primers FIGS11/NPIGS-R also detected DNA extracted from soil infested with conidia from the Fo isolate Fo276. Using a soil dilution series, the lowest detection limit was 150 conidia/g soil (Fig 4).

\section{Evaluation of Biocontrol Potential of Nonpathogenic Fo Isolates}

Seven nonpathogenic $F_{0}$ isolates (Table 1) were evaluated by the pre-inoculation of cucumber seedlings for their potential to delay symptom expression of cucumber Fusarium wilt. Twoweek-old seedlings grown in peat moss infested with the nonpathogenic isolates were transplanted into soil infested with the Foc isolate Foc100 and observed over an 8-wk period for symptom development. Five of the nonpathogenic $F_{0}$ isolates (Fo95022, Fo95024, Fo95026, Fo276 and Fo366) delayed symptom development. Using the FIGS11/NPIGS-R primer pair, the 500-bp fragment was amplified from the IGS DNA of these five isolates. The other two nonpathogenic $F_{0}$ isolates (Fo95020 and Fo95021) failed to delay symptom development, and no PCR product was amplified by the FIGS11/NPIGS-R primer pair in these two isolates (Table 3). Disease severity was suppressed by the $F_{0}$ isolates Fo95024, Fo95026, Fo276 and Fo366 throughout the 8-wk period following the transplantation of seedlings into Foc-infested soil, but isolate Fo95022 suppressed disease severity for only 7 wks. Two $F_{0}$ isolates, Fo276 and Fo95024, were most effective in suppressing disease development; the disease severity ratings they provided after $8 \mathrm{wks}$ were $6 \%$ and $14 \%$, respectively, as compared with a $71 \%$ rating for the control, which was not pre-inoculated (Table 3). The five isolates, Fo276, Fo366, Fo95022, Fo95024 and Fo95026 that showed efficacy on biological control have been deposited to Bioresource Collection and Research Center (BCRG) in Taiwan with accession no. of FU30079, FU30080, FU30081, FU30082 and FU30083, respectively.

\section{Use of FIGS11/NPIGS-R to identify Fo isolates with biocontrol potential}

A total of $77 F_{0}$ isolates isolated from plant tissues and soil from various locations across Taiwan were assayed by PCR using the FIGS11/NPIGS-R primer pair. The amplification of the 500-bp IGS fragment occurred in only six of the $F_{0}$ isolates, including two from plants (isolates Fo7 and SPA7) and four from soil (isolates HS33, OSS11, OSS12, and OSS14) (Table $\mathrm{S} 1$ and Fig S1 with partial gel results). All six isolates identified as PCR positive were found to be nonpathogenic by root dipinoculation of cucumber seedlings in a greenhouse (Table 4). All six isolates identified as PCR positive and shown to be nonpathogenic were found to suppress Fusarium wilt development (Table 5). The disease severity ratings for the plants preinfected with nonpathogenic $F_{0}$ isolates ranged from 9-25\% 8 wks after being transplanted into Foc-infested soil, whereas plants that were not pre-infected received a $63 \%$ disease severity rating (Table 5).

\section{Phylogenetic Analysis of Nonpathogenic Fo Showing Efficacy on Control Cucumber Wilting Based on EF-1 $\alpha$ Gene and IGS Region}

The DNA products of the EF- $1 \alpha$ and IGS region of the five $F_{0}$ isolates (Fo276, Fo366, Fo95022, Fo95024 and Fo95026) amplified by EF-1H/EF-2T and CNS1/CNL12 were 671 bp and 2.4$2.6 \mathrm{~kb}$, respectively. The nucleotide sequences of the EF- $1 \alpha$ and IGS region from these five $F_{0}$ isolates were submitted to GenBank with accession numbers as described as follows: Fo276: KC622306/KC622301, Fo366: KC622307/AB683869, Fo95022: KG622308/KC622302, Fo95024: KC622305/ KC622303 and Fo95026: KC622309/KC622304.

The aligned and truncated EF-1 $\alpha+$ IGS sequences consisted of 2,752 characters, with 2374 characters constant, 148 parsimony uninformative and 230 parsimony informative. The NJ tree constructed from the EF- $1 \alpha+$ IGS region showed that the five isolates of nonpathogenic $F_{0}$ with biological control activity were fell into one group with $80 \%$ bootstrap values and distinct from other pathogenic $F_{0}$ isolates (Fig 5).

\section{Discussion}

Based on the data presented, the new primer NPIGS-R combined with the published general primer FIGS11 [27,30] distinguishes $F_{0}$ isolates that are both nonpathogenic and potential biocontrol agents for Fusarium wilt of cucumber from formae speciales of $F_{0}$ and other nonpathogenic $F_{0}$ isolates that lack biocontrol potential. However, this primer pair does not distinguish nonpathogenic $F_{0}$ isolates lacking biocontrol potential from formae speciales of $F_{0}$. Nonpathogenic $F_{0}$ isolates that recovered from Fusarium wilt-suppressive soils have been extensively studied for antagonistic activity against various formae speciales of $F_{0}$ [8]. There are several reports of nonpathogenic $F_{0}$ isolates being used as biological control agents to manage Fusarium wilt of various crops [9], [10], [11], [12], [13]. However, it has been shown that not all nonpathogenic $F_{0}$ isolates possess biocontrol potential [8], [14]. Currently, bioassay is the only available and reliable method to identify $F_{0}$ isolates with biological control potential, but this assay is very time-consuming and laborious. The highly specific FIGS11/NPIGS-R primer set appears to offer an opportunity to rapidly and efficiently screen large numbers of $F_{0}$ isolates to identify those with biocontrol potential.

These new molecular tools were used to investigate the genetic relationships among pathogenicity, biological control and saprophytic $F_{0}$ and to elucidate the genetic determinants of pathogenicity and biological control ability. Appel and Gordon [27] showed an interaction between pathogenic and nonpathogenic $F_{0}$ and addressed the differences in pathogenic race, vegetative compatibility group (VCG), mitochondrial DNA (mDNA) haplotype and IGS haplotype, but could not directly separate nonpathogenic $F_{0}$ from pathogenic $F_{0}$. Therefore, the genetic basis of pathogenic, nonpathogenic or biocontrol strains of $F_{0}$ remains unclear [39], [40]. In this study, we developed a molecular marker to differentiate the Taiwanese nonpathogenic $F_{0}$ isolates from the pathogenic isolates on cucumbers (Fig 1). The primers FIGS11/NPIGS-R were able to specifically amplify a DNA product from the $F_{0}$ isolates that showed potential for 
controlling Fusarium wilt of cucumber (Table 1 and Fig 2). The variation in the intergenic spacer (IGS) region of ribosomal DNA is useful for resolving intra-specific relationships within $F_{0}$ [23], [25], [26]. It has been suggested that the variation in the IGS of rDNA may have a considerable effect on development, evolution, and ecology through its effects on growth-rate regulation, resulting from the role of the IGS in the production of rRNA [41]. This study suggests that the variation in the IGS region could differentiate the $F_{0}$ isolates with biological control abilities from the pathogenic and the nonpathogenic Fo isolates that did not have biocontrol potential.

The $F_{0}$ isolates Fo95020 and Fo95021, which showed no PCRamplified 500-bp product with the primers FIGS 11 and NPIGS$\mathrm{R}$, were unable to delay the disease progression of Fusarium wilt of cucumber in a greenhouse experiment. According to this result, we speculated that these two isolates might belong to one of the $F_{0}$ formae speciales or a saprophytic one that lacks the biological control ability for Fusarium wilt of cucumber. To relieve the concern about the pathogenicity of the nonpathogenic $F_{0}$ used in this study, the $F_{0}$ isolates Fo276 and Fo366 were tested for their pathogenicity on fourteen species of the main cultivated crops or vegetables (such as asparagus bean, basil, bitter gourd, cucumber, loofah, melon, pea, radish, snap bean, spinach, sweet potato, tomato, watermelon and wax gourd) in Taiwan, and the results showed that no symptoms were induced on the inoculated plants by either isolate (Wang, unpublished data). This lack of symptoms may be because the nonpathogenic $F_{0}$ isolates were defined as those that "failed to induce disease on a limited number of plant species to which they had been inoculated" [14]. Therefore, the pathogenicity test may lead to problems in differentiating the isolates. Future research will focus on the utilization of the primers FIGS 11 and NPIGS-R to screen more $F_{0}$ isolates with biological control ability and to reveal the difference in genomic or IGS sequence between the pathogenic and nonpathogenic isolates.

The sensitivity of this PCR assay with the primers FIGS11 and NPIGS-R was shown to detect as low as $1 \times 10^{-2} \mathrm{ng}$ of fungal DNA. Such minute amounts of fungal DNA can be obtained easily from several natural substrates or living plant tissues that harbor the target strains. Moreover, 77 isolates of $F_{0}$ from soil and plants tissues were screened and examined with FIGS11 and NPIGS-R. The results obtained demonstrated that only six isolates could be detected by FIGS 11 and NPIGS-R. To confirm pathogenicity, the isolates that were amplified by FIGS11 and NPIGS-R had been tested for pathogenicity to cucumber, and no symptoms occurred in plants after inoculation. Meanwhile, these newly selected isolates have shown efficacy in delaying the disease progression of Fusarium wilt of cucumber in a greenhouse experiment. Thus, the newly developed molecular detection method with the primers FIGS11 and NPIGS-R may have practical applications in the study of the epidemiology, fungal population genetics, and even the mechanism of nonpathogenic strains in combating Fusarium wilt diseases [21]. Moreover, as mentioned in the Materials and Methods, the reason why Fo366 lost its biocontrol potential is unknown, but mutation was suspected [42]. This finding reemphasized that additional $F_{0}$ isolates with biological control ability are needed and reaffirms the significance of this new reliable and highly specific protocol in the identification of the biocontrol potential of $F_{0}$ isolates. In addition, several studies on Fusarium disease show that mixtures of biocontrol agents have provided better control and that a range of biocontrol mechanisms may operate in mixed populations of biocontrol agents [8], [43], [44]. Moreover, different biocontrol mechanisms have been shown among different nonpathogenic $F_{0}$ isolates [8] and, the combination of different nonpathogenic $F_{0}$ isolates might use multiple mechanisms to control the Fusarium wilt disease and provide better control efficacy.

Previous studies revealed that the Fusarium oxysporum is a species complex (FOSC) containing several groups of isolates with differently pathogenic activity on human and plants (Ma et al., 2010 [45], O’Donnell et al., 2004 [33], O’Donnell et al., 2009 [46]). Our result demonstrated that some nonpathogenic $F_{0}$ isolates of FOSC that showed positive reaction to PCR have activity on controlling Fusarium wilt of cucumber. According to the molecular topology, the $F$. oxysporum with pathogenicity on human or plants were scattered in different molecular groups. The scattered phenomenon of topology in human and plant $F_{0}$ pathogens was also confirmed by O'Donnell et al. (2009 [46]). They also mentioned that the evolutionary relationships between plant pathogens and nonpathogenic $F_{0}$ (untested with the biological control activity) were nested and still unclear (O'Donnell et al., 2009 [46]). However, the isolates of nonpathogenic $F_{0}$ with biological control ability were grouped into a unique clade and differentiated from other reference isolates of human and plant pathogens in this study. Along with these results, the nonpathogenic $F_{0}$ isolates with biological control ability amplified by FIGS11/NPIGS-R were monophylogeny. Thus, the newly designed primer is indeed with the ability of specificity and peculiarity in detecting the nonpathogenic $F_{0}$ with biological control ability in Taiwan.

In the future, additional isolates of different formae speciales and $F_{0}$ nonpathogenic to cucumber from various geographic origins will be used to further confirm the specificity of our PCR assay method for identifying nonpathogenic $F_{0}$ isolates with biocontrol potential. Further studies will determine whether the markers can be used worldwide.

\section{Supporting Information}

Figure S1 Use of FIGS11/NPIGS-R to identify Fo isolates with biocontrol potential. Agarose gels showing amplification products of partial isolates of Fusarium oxysporum obtained from soils and plant tissues from the field by polymerase chain reaction (PCR). (A): DNA products, 550 to 650 bp in length, were amplified from isolates of $F$. oxysporum by FIGS11 and FIGS12; (B): DNA products, 500 bp in length, were amplified from isolates of $F$. oxysporum by FiGS11 and NPIGS-R. The numbers on the left are the molecular weights $(\mathrm{Kb})$ of the Gen100 bp DNA ladder (GeneMark) (lane M). Lanes 1 to 17 represented the Fusarium oxysporum isolates, which were collected from fields, and lanes 18 to 23 represented the nonpathogenic Fusarium oxysporum isolates Fo7, HS33, OSS11, OSS12, OSS14 and SPA7.

(TIFF)

Table S1 Screening of 77 Fusarium oxysporum isolates using PGR with the primers FIGS11 and NPIGS-R. (DOG)

\section{Acknowledgments}

We sincerely thank Dr. Chung-Jan Chung, Professor Emeritus, Department of Plant Pathology, College of Agricultural and Environmental Sciences, University of Georgia and Dr. Black Lowell, Plant Pathologist, Seminis Vegetable Seeds for their critical review of the manuscript. We are grateful to Drs. J. W. Huang (NCHU), P. F. Linda Chang (NCHU), P. H. Wang (THU) and T. C. Wang (AVRDG) for providing the ATCG type strains and the tested pathogenic or avirulent $F$. oxysporum isolates; Dr. C. Y. Chen (NCHU) for providing and identifying the different $F$. species. 


\section{Author Contributions}

Conceived and designed the experiments: CJW YSL YHL WHC. Performed the experiments: CJW YSL YHL WHC. Analyzed the data:

\section{References}

1. Gordon TR, Okamoto D (1990) Colonization of crop residue by Fusarium oxysporum f. sp. melonis and other species of Fusarium. Phytopathology 80: 381386.

2. Gordon TR, Okamoto D (1992) Population structure and the relationship between pathogenic and nonpathogenic strains of Fusarium oxysporum. Phytopathology 82: 73-77.

3. Gordon TR, Okamoto D, Milfroom MG (1992) The structure and interrelationship of fungal populations in native and cultivated soils. Mol Ecol 1: $241-249$.

4. Fourie G, Steenkamp E, Ploetz R, Gordon T, Viljoen A (2011) Current status of the taxonomic position of Fusarium oxysporum formae specialis cubense within the Fusarium oxysporum complex. Infect Genet Evol 11: 533-542.

5. Vakalounkis DJ, Fragkiadakis GA (1999) Genetic diversity of Fusarium oxysporum isolates from cucumber: Differentiation by pathogenicity, vegetative compatibility, and RAPD fingerprinting. Phytopathology 89: 161-169.

6. Erwin DC (1981) Chemical control. In: Marashall EM, Alois AB, Carl HB, editors. Fungal wilt Disease of Plants. New York: Academic Press. 563-594.

7. Lazarovits G, Tenuta M, Conn KL (2001) Organic amendments as a disease control strategy for soilborne diseases of high-value agricultural crops. Australasian Plant Pathol 30: 111-117.

8. Fravel D, Olivain C, Alabouvette G (2003) Research review: Fusarium oxysporum and its biocontrol. New Phytol 157: 493-502.

9. Larkin RP, Fravel DR (1999) Mechanisms of action and dose-response relationships governing biological control of Fusarium wilt of tomato by nonpathogenic Fusarium spp. Phytopathology 89: 1152-1161.

10. Ogura K, Komada H (1984) Biological control of Fusarium wilt of sweet potato by nonpathogenic Fusarium oxysporum. Ann Phytopathol Soc Japan 50:1-9.

11. Lemanceau P, Bakker PA, Kogel WJD, Alabouvette C, Schippers B (1992) Effect of pseudobactin 358 production by Pseudomonas putida WCS358 on suppression of fusarium wilt of carnations by nonpathogenic Fusarium oxysporum Fo47. Appl Environ Microbiol 58: 2978-2982.

12. Chen JF (1999) Identification of Fusarium wilt of cucumber and screening of nonpathogenic Fusarium oxysporum for the disease control. Taichung. Taiwan, ROC: National Chung Hsing University. Master's thesis.

13. Wang CJ (2006) Study of nonpathogenic Fusarium oxysporum in controlling Fusarium wilt of cucumber and asparagus bean. Taichung. Taiwan, ROC: National Chung Hsing University. Master's thesis.

14. Alabouvette C, Lemanceau P, Steinberg C (1996) Biological control of Fusarium wilts: opportunities for developing a commercial product. In: Hall R, editor. Managing Soilborne Plant Pathogens. Minnesota: APS Press. 192-212.

15. Deacon JW (2006) Fungal genetics, molecular genetics, and genomics. In: Deacon JW, editor. Fungal biology. New York: Blackwell Press. 158-183.

16. Jurado M, Vázquez C, Marín S, Sanchis V, González-Jaéna MT (2006) PCRbased strategy to detect contamination with mycotoxigenic Fusarium species in maize. Syst Appl Microbiol 29: 681-689.

17. Schilling AG, Möller EM, Geiger HH (1996) Polymerase chain reaction-based assays for species-specific detection of Fusarium culmorum, $F$. graminearum, and $F$. avenaceum. Phytopathology 86: 515-523.

18. Wilson A, Simpson D, Chandler E, Jennings P, Nicholson P (2004) Development of PCR assays for the detection and differentiation of Fusarium sporotrichioides and Fusarium langsethiae. FEMS Microbiol Lett 233: 69-76.

19. Yergeau E, Filion M, Vujanovic V, St-Arnaud M (2005) A PCR-denaturing gradient gel electrophoresis approach to assess Fusarium diversity in asparagus. J Microbiol Methods 60: 143-154

20. Lievens B, Rep M, Thomma BPHJ (2008) Recent developments in the molecular discrimination of formae speciales of Fusarium oxysporum. Pest Manag Sci 64: 781-788.

21. Lin YH, Chang JY, Liu ET, Chao CP, Huang JW, et al. (2009) Development of molecular marker for specific detection of Fusarium oxysporum f. sp. cubense race 4. Eur J Plant Pathol 123: 353-365.

22. Dissanayake MLMC, Kashima R, Tanaka S, Ito S (2009) Pathogenic variation and molecular characterization of Fusarium species isolated from wilted Welsh onion in Japan. J Gen Plant Pathol 75: 37-45.

23. Edel-Hermann V, Gautheron N, Steinberg C (2012) Genetic diversity of Fusarium oxysporum and related species pathogenic on tomato in Algeria and other Mediterranean countries. Plant Pathol 61: 787-800.

24. Kawabe M, Katsube K, Yoshida T, Arie T, Tsuchiya K (2007) Genetic diversity of Fusarium oxysporum f. sp. spinaciae in Japan based on phylogenetic analyses of rDNA-IGS and MAT1 sequences. J Gen Plant Pathol 73: 353-359.
GJW YSL WHC. Contributed reagents/materials/analysis tools: GJW YSL YHL WHC. Wrote the paper: CJW YSL WHC.

25. Lori G, Edel-Hermann V, Gautheron N, Alabouvette G (2004) Genetic diversity of pathogenic and nonpathogenic populations of Fusarium oxysporum isolated from carnation fields in Argentina. Phytopathology 94: 661-668.

26. Srinivasan K, Spadaro D, Poli A, Gilardi G, Gullino ML, et al. (2012) Genetic diversity and pathogenicity of Fusarium oxysporum isolated from wilted rocket plants in Italy. Phytoparasitica 40: 157-170.

27. Appel DJ, Gordon TR (1996) Relationships among pathogenic and nonpathogenic isolates of Fusarium oxysporum based on the partial sequence of the intergenic spacer region of the ribosomal DNA. Mol Plant-Microbe Interact 9: 125-138.

28. Nash SM, Snyder WC (1962) Quantitative estimation by plate counts of propagules of the bean root rot Fusarium in field soils. Phytopathology 52: 567572 .

29. Saitoh K, Togashi K, Arie T, Teraoka T (2006) A simple method for a minipreparation of fungal DNA. J Gen Plant Pathol 72: 348-350.

30. Kawabe M, Kobayashi Y, Okada G, Yamaguchi I, Teraoka T, et al. (2005) Three evolutionary lineages of tomato wilt pathogen, Fusarium oxysporum $\mathrm{f}$. sp. lycopersici, based on sequences of IGS, MAT1, and pg1, are each composed of isolates of a single mating type and a single or closely related vegetative compatibility group. J Gen Plant Pathol 71: 263-272.

31. Scher FM, Baker R (1982) Effect of Pseudomonas putida and a synthetic iron chelator on induction of soil suppressiveness to Fusarium wilt pathogens. Phytopathology 72: 1567-1573.

32. O'Donnell K, Sutton DA, Rinaldi MG, Magnon KC, Cox PA, et al. (2004) Genetic diversity of human pathogenic members of the Fusarium oxysporum complex inferred from multilocus DNA sequence data and amplified fragment length polymorphism analyses: evidence for the recent dispersion of a geographically widespread clonal lineage and nosocomial origin. J Clin Microbiol 42: 5109-5120.

33. Ortoneda M, Guarro J, Madrid MP, Caracuel Z, Roncero MIG. et al. (2004) Fusarium oxysporum as a multihost model for the genetic dissection of fungal virulence in plants and mammals. Infect Immunity 72: 1760-1766.

34. Mbofung GY, Hing SG, Pryor BM (2007) Phylogeny of Fusarium oxysporum f. sp. lactucae Inferred from Mitochondrial Small Subunit, Elongation Factor 1-alpha, and Nuclear Ribosomal Intergenic Spacer Sequence Data. Phytopathology 97: 87-98.

35. Thompson JD, Gibson TJ, Plewniak F, Jeanmougin F, Higgins DG (1997) The Clustal $\mathrm{X}$ windows interface: flexible strategies for multiple sequence alignment aided by quality analysis tools. Nucleic Acids Res 25: 4876-4882.

36. Rambaut A (2000) Se-Al: Sequence Alignment Editor. Oxford, UK: Department of Zoology, University of Oxford.

37. Kimura M (1980) A simple method for estimating evolutionary rate of base substitutions through comparative studies of nucleotide sequences. J Mol Evol 16: 111-120.

38. Felsenstein J (1985) Confidence limits on phylogenies: an approach using the bootstrap. Evolution 39: 783-791.

39. Appel DJ, Gordon TR (1995) Intraspecific variation within populations of Fusarium oxysporum based on RFLP analysis of the intergenic spacer (IGS) region of the rDNA. Exp Mycol 19: 120-128.

40. Recorbet G, Steinberg C, Olivain C, Edel V, Trouvelot S, et al. (2003) Wanted: pathogenesis-related marker molecules for Fusarium oxysporum. New Phytol 159: 73-92.

41. Gorokhova E, Dowling TE, Weider LJ, Crease TJ, Elser JJ (2002) Functional and ecological significance of rDNA intergenic spacer variation in a clonal organism under divergent selection for production rate. Proc Biol Sci 269: 23732379.

42. Zhang Z, Yuen GY, Sarath G, Penheiter AR (2001) Chitinases from the plant disease biocontrol agent, Stenotrophomonas maltophilia C3. Phytopathology 91: 204 211.

43. Xu XM, Jeffries P, Paurasso M, Jeger MJ (2011) Combined Use of Biocontrol Agents to Manage Plant Diseases in Theory and Practive. Phytopathology 101: 1024-1031.

44. Guetsky R, Shtienberg D. Elad Y, Fischer E, Dinoor A (2002) Improving biological control by combining biocontrol agents each with several mechanisms of disease suppression. Phytopathology 92: 976-985.

45. Ma LJ, van der Does HC, Borkovich KA, Coleman JJ, Daboussi MJ, et al. (2010) Comparative genomics reveals mobile pathogenicity chromosomes in Fusarium. Nature 464: 367-373.

46. O'Donnell K, Gueidan C, Sink S, Johnston PR, Crous PW, et al. (2009) A twolocus DNA sequence database for typing plant and human pathogens within the Fusarium oxysporum species complex. Fungal Genet Biol 46: 936-948. 